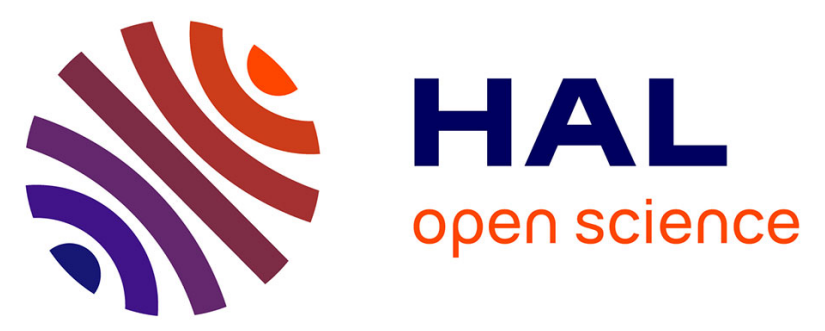

\title{
Longitudinal Dependence of Whistler Mode Electromagnetic Waves in the Earth's Inner Magnetosphere
}

J. Záhlava, F. Němec, O. Santolík, I. Kolmašová, G. Hospodarsky, Michel Parrot, W. Kurth, J. Bortnik, C. Kletzing

\section{To cite this version:}

J. Záhlava, F. Němec, O. Santolík, I. Kolmašová, G. Hospodarsky, et al.. Longitudinal Dependence of Whistler Mode Electromagnetic Waves in the Earth's Inner Magnetosphere. Journal of Geophysical Research Space Physics, 2018, 123 (8), pp.6562 - 6575. 10.1029/2018JA025284 . insu-01897671

\section{HAL Id: insu-01897671 https://hal-insu.archives-ouvertes.fr/insu-01897671}

Submitted on 24 Oct 2018

HAL is a multi-disciplinary open access archive for the deposit and dissemination of scientific research documents, whether they are published or not. The documents may come from teaching and research institutions in France or abroad, or from public or private research centers.
L'archive ouverte pluridisciplinaire HAL, est destinée au dépôt et à la diffusion de documents scientifiques de niveau recherche, publiés ou non, émanant des établissements d'enseignement et de recherche français ou étrangers, des laboratoires publics ou privés. 


\section{Journal of Geophysical Research: Space Physics}

\section{RESEARCH ARTICLE}

10.1029/2018JA025284

Key Points:

- Longitudinal dependence of whistler mode waves in the inner magnetosphere is investigated

- Significant longitudinal dependence at frequencies between about 0.4 and $2 \mathrm{kHz}$ is found inside the plasmasphere

- The dependence is primarily observed on the nightside and is likely related to lightning activity

Correspondence to:

J. Záhlava,

jan.zahlava@gmail.com

Citation:

Záhlava, J., Němec, F., Santolík, O., Kolmašova, I., Hospodarsky, G. B., Parrot, M., et al. (2018). Longitudinal dependence of whistler mode electromagnetic waves in the Earth's inner magnetosphere. Journal of Geophysical Research: Space Physics, 123, 6562-6575. https://doi.org/10.1029/2018JA025284

Received 29 JAN 2018 Accepted 18 JUL 2018 Accepted article online 25 JUL 2018 Published online 21 AUG 2018

○2018. American Geophysical Union All Rights Reserved.

\section{Longitudinal Dependence of Whistler Mode Electromagnetic Waves in the Earth's Inner Magnetosphere}

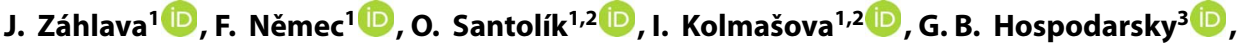 \\ M. Parrot ${ }^{4}$, W. S. Kurth ${ }^{3}$, J. Bortnik ${ }^{5}$, and C. Kletzing ${ }^{3}$ iD \\ ${ }^{1}$ Faculty of Mathematics and Physics, Charles University, Prague, Czech Republic, ${ }^{2}$ Department of Space Physics, Institute \\ of Atmospheric Physics, The Czech Academy of Sciences, Prague, Czech Republic, ${ }^{3}$ Department of Physics and Astronomy, \\ University of lowa, lowa City, IA, USA, ${ }^{4}$ LPC2E/CNRS, Orléans, France, ${ }^{5}$ Department of Atmospheric and Oceanic Sciences, \\ University of California, Los Angeles, CA, USA
}

Abstract We use the measurements performed by the DEMETER (2004-010) and the Van Allen Probes (2012-016, still operating) spacecraft to investigate the longitudinal dependence of the intensity of whistler mode waves in the Earth's inner magnetosphere. We show that a significant longitudinal dependence is observed inside the plasmasphere on the nightside, primarily in the frequency range $400 \mathrm{~Hz}$ to $2 \mathrm{kHz}$. On the other hand, almost no longitudinal dependence is observed on the dayside. The obtained results are compared to the lightning occurrence rate provided by the Optical Transient Detector/Lightning Imaging Sensor mission normalized by a factor accounting for the ionospheric attenuation. The agreement between the two dependencies indicates that lightning-generated electromagnetic waves may be responsible for of the observed effect, thus substantially affecting the overall wave intensity in the given frequency range. Finally, we show that the longitudinal dependence is most pronounced for waves with oblique wave of normal angles.

\section{Introduction}

A large variety of electromagnetic waves of various origins propagate in the plasma environment of the Earth's inner magnetosphere. At frequencies below the electron cyclotron frequency (or the electron plasma frequency, whichever is lower), the electromagnetic waves propagate in the so-called whistler mode (Stix, 1992). These waves can efficiently interact with energetic electrons in the Van Allen radiation belts. Chorus, plasmaspheric hiss, equatorial noise, lightning-generated whistlers, and signals from artificial very low frequency (VLF) transmitters are perhaps the most prominent examples of this type of electromagnetic wave mode.

Chorus emissions usually occur outside the plasmasphere (Burtis \& Helliwell, 1969; Meredith et al., 2001). They are typically formed by discrete nonlinear wave packets (Santolík et al., 2014) confined to two frequency intervals related to the equatorial electron cyclotron frequency $\left(f_{c e}\right)$. The lower chorus band spans approximately from 0.1 to $0.45 f_{c e}$, while the frequencies of the upper chorus band range from about 0.5 to $0.7 f_{c e}$ (Tsurutani \& Smith, 1974, 1977). Chorus is generated by the cyclotron resonance interaction of embryonic waves with energetic electrons in the outer radiation belt (e.g., Li et al., 2009, 2008; Omura et al., 2008).

Plasmaspheric hiss is an incoherent structureless emission typically observed in the frequency range from about $100 \mathrm{~Hz}$ up to several kilohertz (Hayakawa \& Sazhin, 1992), but it can occur at frequencies as low as a few tens of hertz (Li et al., 2013). Plasmaspheric hiss is the most intense at frequencies between about 100 and $300 \mathrm{~Hz}$. (Li et al., 2015; Thorne et al., 1973; Tsurutani et al., 2012), and its intensity rapidly decreases at frequencies larger than about $1 \mathrm{kHz}$ (Meredith, Horne, Clilverd, et al., 2006). As the name suggests, it is observed nearly exclusively inside the plasmasphere (Meredith et al., 2004; Thorne et al., 1973). It is responsible for the formation of the slot region due to the pitch angle scattering of the trapped electrons in a wide range of energies from several tens of kiloelectron volts up to the order of megaelectron volts (Abel \& Thorne, 1998a, 1998b; Lyons \& Thorne, 1973; Meredith et al., 2007, 2009; Meredith, Horne, Glauert, et al., 2006; Ni et al., 2013; Thorne et al., 2013). It has been suggested that the plasmaspheric hiss might originate as chorus penetrating inside the plasmasphere (e.g., Bortnik, Chen, Li, Thorne, \& Horne, 2011; Bortnik, Chen, Li, Thorne, Meredith, \& Horne, 2011; Bortnik et al., 2009, 2008; Chen, Li, et al., 2012; Chen et al., 2012a, 2012b; Chum \& Santolík, 2005; 
a)

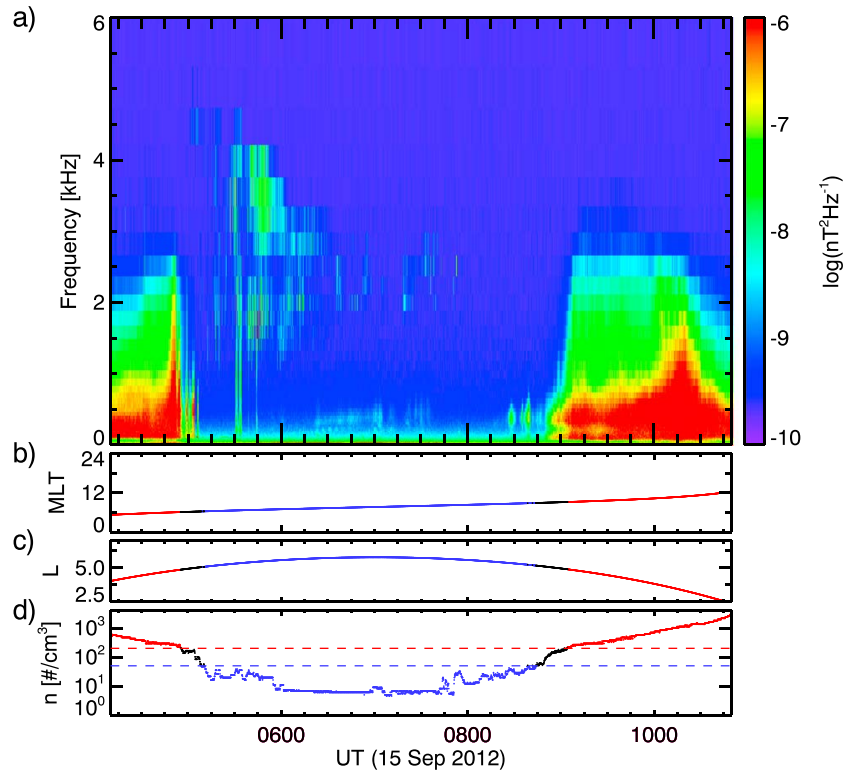

Figure 1. (a) Frequency-time spectrogram of magnetic power spectral density fluctuations measured by Van Allen Probe A on 15 September 2012 between about 04:10 and 10:50 UT. (b) Magnetic local time (MLT). (c) L-shell of the spacecraft. (d) Plasma number density. The red and blue colors in panels (b) and (d) indicate the time intervals when the spacecraft was considered to be located inside and outside the plasmasphere, respectively. The dashed horizontal lines in panel (c) represent the appropriate plasma number density thresholds.
Church \& Thorne, 1983; Li et al., 2015; Santolík, Chum, et al., 2006). However, the complete understanding of its origin is still an open question (Green et al., 2005, 2006; Laakso et al., 2015; Meredith, Horne, Clilverd, et al., 2006; Santolík \& Chum, 2009; Thorne et al., 2006).

Lightning strokes produced during thunderstorms in the Earth's atmosphere emit wide-band electromagnetic waves (spherics), which subsequently propagate in the waveguide formed by the surface of the Earth and the bottomside of the ionosphere. These waves eventually escape the waveguide and propagate through the ionosphere toward higher altitudes. There are two principal ways of propagation of these electromagnetic waves through the magnetospheric plasma environment, resulting in either ducted or unducted whistlers (Fišer et al., 2010; Santolík et al., 2009; Walker, 1976). The ducted whistlers propagate inside a duct formed by plasma of a slightly different density aligned with the ambient magnetic field (Helliwell, 1965). On the other hand, the trajectory of the unducted whistlers generally does not follow the ambient magnetic field line, but it is governed by the gradients of the refractive index of the plasma medium. Lightning-generated whistlers are directly responsible for lightning-induced electron precipitation events (Bortnik et al., 2006; Inan et al., 2007; Peter \& Inan, 2004, 2007). They have also been suggested as one of the possible sources of plasmaspheric hiss (e.g., Draganov et al., 1992; Green et al., 2005; Sonwalkar \& Inan, 1989). A comprehensive modeling study of how lightning whistlers could turn into hiss was performed by Bortnik et al. (2003a).

Several studies have focused on the effects of lightning-generated whistlers on the overall VLF wave intensity in the Earth's plasma environment. Němec, Santolík, et al. (2010) utilized the seasonal variation of lightning occurrence to demonstrate that the wave intensity at an altitude of about $700 \mathrm{~km}$ has a similar seasonal variation, in particular during the night. Furthermore, Colman and Starks (2013) analyzed both seasonal and diurnal dependencies of the average lightning occurrence rates along with the ionospheric attenuation curves calculated by Helliwell (1965) to estimate the geographic distribution of a pseudopower generated by lightning propagating to the altitude of $700 \mathrm{~km}$. A comparison with the wave data measured by the low-altitude DEMETER spacecraft shows a reasonable agreement. Based on the geographic distribution of the detected wave intensity, Green et al. (2005) argued that lightning-generated whistlers are possibly a primary source of the plasmaspheric hiss. This statement was opposed by Thorne et al. (2006) and Meredith, Horne, Clilverd, et al. (2006) who pointed out different frequency ranges of the two wave phenomena. While the lightning-generated emissions appear to be dominant at higher frequencies, no evidence that they affect plasmaspheric hiss at lower frequencies has been found in these studies.

Statistical studies of the wave phenomena in the Earth's inner magnetosphere are often focused on the analysis of the wave intensity as a function of frequency, L-shell, magnetic local time (MLT), and geomagnetic activity. In the present study, we focus on the dependence of the median wave intensity on the geomagnetic longitude. Since the wave phenomena originating at larger radial distances should not depend on the longitude, we suggest that any longitudinal dependence observed should be of a terrestrial origin. Given the analyzed frequency range, which is well below the frequencies of powerful VLF transmitters, electromagnetic emissions generated by lightning activity are expected to be the most significant terrestrial contributor. Several studies already focused on the longitude as a controlling factor (Green et al., 2005; Meredith, Horne, Clilverd, et al., 2006). They observed the enhanced wave intensity above the landmass at frequencies above $0.5 \mathrm{kHz}$ and above $2 \mathrm{kHz}$, respectively. Additionally, they also showed that the longitudinal dependence was better pronounced during the northern summer. DEMETER and Van Allen Probes provide large data sets with a very good frequency resolution in the most problematic range. It is therefore possible to investigate the frequency dependence of the longitudinal variation in more detail. Moreover, a thorough analysis of its MLT dependence can be performed due to the complete coverage of the Van Allen Probes. The data sets used are introduced in section 2, and the obtained results are described in section 3 . They are discussed in section 4 and briefly summarized in section 5 . 


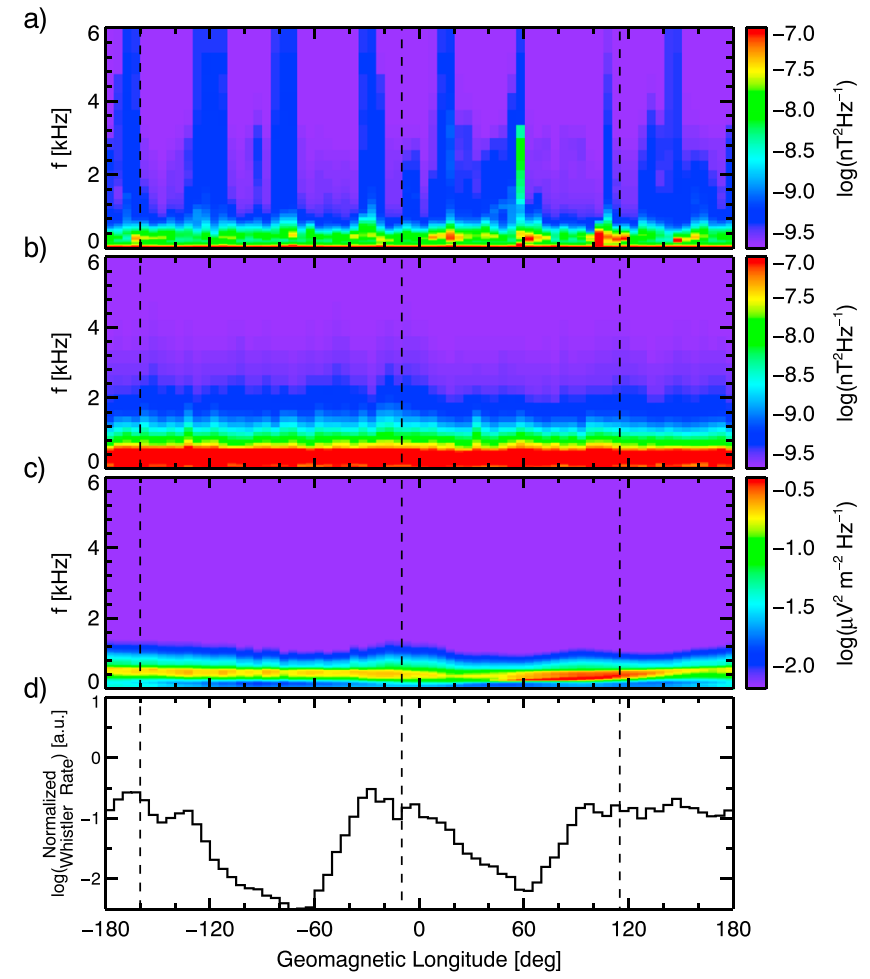

Figure 2. (a) Median power spectral density of magnetic field fluctuations measured by Van Allen Probes outside the plasmasphere in the magnetic local time interval from 9 to $12 \mathrm{hr}$ as a function of frequency and geomagnetic longitude. (b) Same as (a) but inside the plasmasphere. (c) Median power spectral density of electric field fluctuations measured by the DEMETER spacecraft during the daytime half-orbits as a function of frequency and geomagnetic longitude. (d) Average lightning occurrence rate in the local time interval 8-12 hr normalized by the ionospheric attenuation factor as a function of the geomagnetic longitude. The dashed lines mark the longitudinal positions of the largest normalized lightning occurrence rates.

\section{Data Sets}

The French microsatellite DEMETER operated between July 2004 and December 2010 on an approximately circular polar orbit with an altitude of about $700 \mathrm{~km}$. The orbit was nearly Sun synchronous, that is, the measurements were performed in two distinct local time intervals (approximately 10:30 and 22:30 LT). We will hereafter refer to these time intervals as daytime and nighttime, respectively. The wave instruments onboard measured both electric (Berthelier et al., 2006) and magnetic (Parrot et al., 2006) fields at geomagnetic latitudes lower than $65^{\circ}$. Frequency-time spectrograms of power spectral density of one electric and one magnetic field component in the frequency range up to $20 \mathrm{kHz}$ were calculated onboard with a time resolution of about $2 \mathrm{~s}$ and frequency resolution of about $19.53 \mathrm{~Hz}$. The magnetic field measurements in this frequency range, however, contain a substantial amount of spacecraft interference, and thus, they are not used in the present study.

We also use data from the two Van Allen Probes that operate on nearly similar elliptical orbits close to the equatorial plane. The perigee is at an altitude of about $600 \mathrm{~km}$, and the apogee at a radial distance of about 5.8 Earth radii. We analyze the data obtained from the beginning of the mission in August 2012 until the end of 2016. The measurements cover a wide range of L-shells (from about 1.05 up to about 6.5), and a complete set of combinations of MLTs and geomagnetic longitudes. The Electric and Magnetic Field Instrument Suite and Integrated Science instrument suite's Waves instrument (Kletzing et al., 2013) performs multicomponent wave measurements in the frequency range between $10 \mathrm{~Hz}$ and $12 \mathrm{kHz}$. In the survey mode, the spectral matrices of three magnetic and three electric field components are calculated onboard with a time resolution of $6 \mathrm{~s}$. The frequency range is divided into 65 intervals with approximately logarithmically distributed bandwidths. Power spectral densities, along with wave propagation parameters calculated using the analysis algorithms designed by Santolík et al. (2001), Santolík and Gurnett (2002), Santolík et al., $(2003,2010)$, are used in this study. Moreover, the evaluation of the upper hybrid frequency can be used to determine the local plasma number density (Kurth et al., 2015).

Other data for this study were obtained from the Optical Transient Detector (OTD) and Lightning Imaging Sensor (LIS) missions (1995-2011) which were devoted to the optical detection of tropospheric lightning. The data set used provides us with average lightning occurrence rates with a spatial resolution of $2.5^{\circ}$, both in geographic latitude and longitude, and a 2-hr local time resolution (Cecil et al., 2014).

\section{Results}

An example of a frequency-time spectrogram of magnetic power spectral density measured by the Van Allen Probe A spacecraft on 15 September 2012 between about 04:10 UT and 10:50 UT is shown in Figure 1a in a subinterval of frequencies below $6 \mathrm{kHz}$. Figure $1 \mathrm{~b}$ shows the MLT of the spacecraft, Figure $1 \mathrm{c}$ the corresponding L-shell of the spacecraft, and Figure $1 \mathrm{~d}$ the local plasma number density. The plasma number density is used, along with the spacecraft L-shell, to distinguish whether the spacecraft was located inside or outside the plasmasphere. Specifically, all the measurements at $L \leq 2.5$ are considered to be inside the plasmasphere and are marked by the red color in the MLT, $L$, and density plots in Figures $1 \mathrm{~b}-1 \mathrm{~d}$, respectively. The measurements performed at $L>2.5$ are divided into three groups based on the local plasma number density. (i) The locations with plasma number density larger than $200 \mathrm{~cm}^{-3}$ are considered to be inside the plasmasphere and are also marked by the red color in Figures $1 \mathrm{~b}-1 \mathrm{~d}$; (ii) the locations with plasma number density lower than $50 \mathrm{~cm}^{-3}$ are considered to be outside the plasmasphere and are marked by the blue color in Figures $1 \mathrm{~b}$ and 1c. The respective density thresholds are marked by the horizontal dashed lines in the density plot. (iii) All the remaining cases are considered to be performed neither inside nor outside the plasmasphere and thus are 
a)
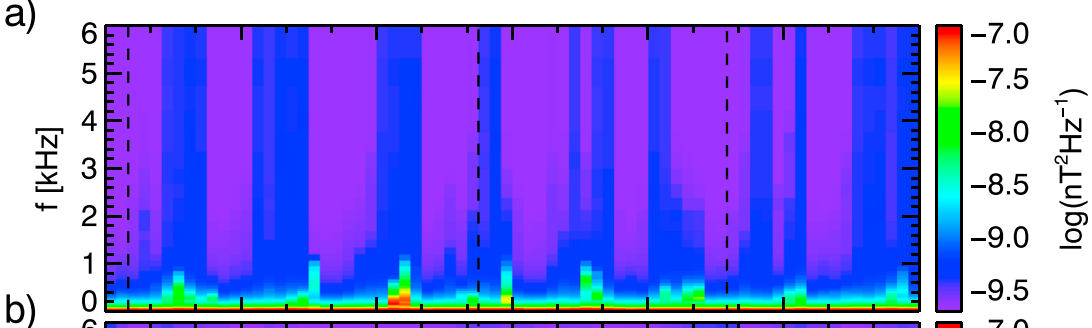

b)

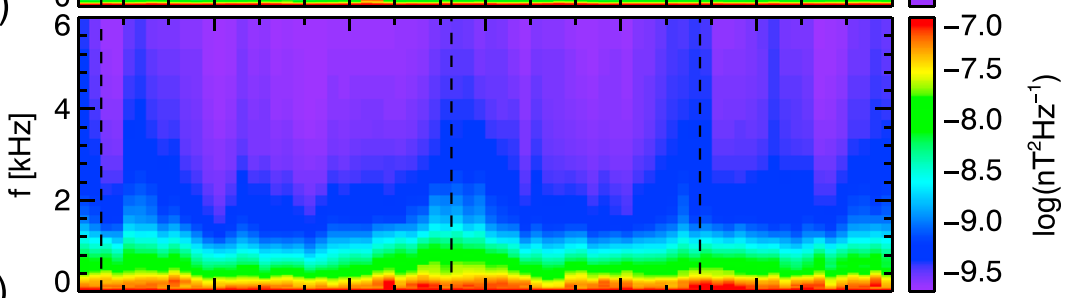

c)

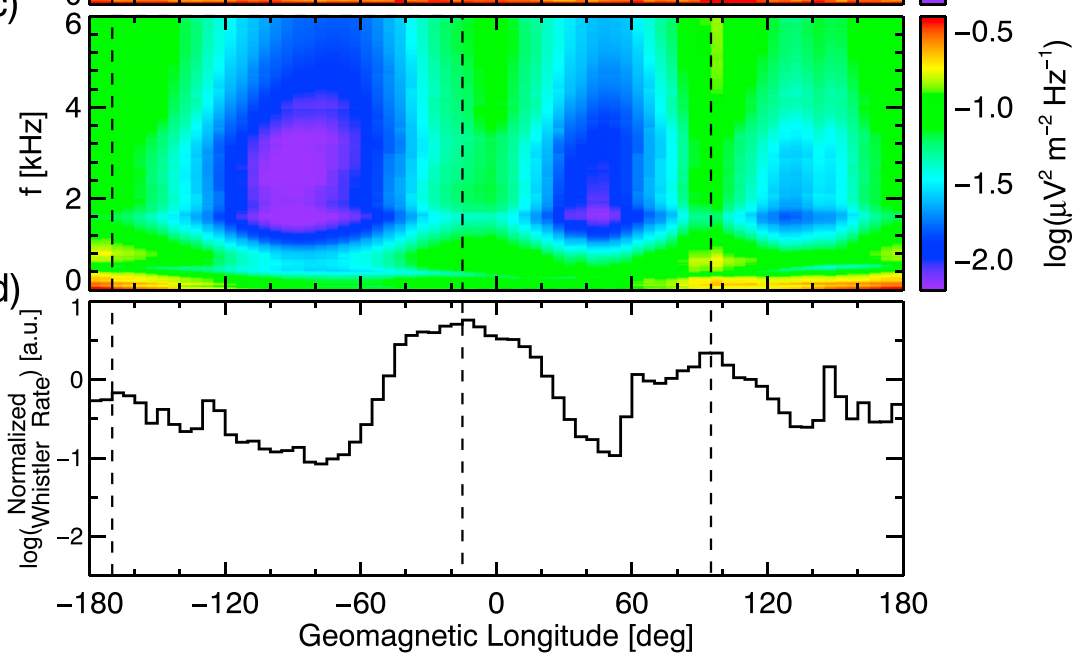

Figure 3. Same as Figure 2 but for the magnetic local time interval $21-24 \mathrm{hr}$ (panels a, b), nighttime half-orbits (panel c), and for local time interval from 20 to $24 \mathrm{hr}$ (panel d). Only data measured at the times of $A E<100$ are used.

effectively excluded from further analysis. We also note that the difference between the wave activity inside the plasmasphere (the beginning and ending of the plotted time interval) and outside the plasmasphere (the middle of the plotted time interval) is striking. While there is principally no wave activity observed outside the plasmasphere in this case, significant wave intensities are detected inside the plasmasphere. The analysis hereafter is thus performed separately for observations inside and outside the plasmasphere. In the statistical approach used, it is not possible to distinguish between chorus, plasmaspheric hiss, and lightning-generated whistlers. However, we assume that treating the measurements performed by the Van Allen Probes inside and outside the plasmasphere individually should effectively separate chorus from the latter emissions.

Given the limited MLT coverage of the DEMETER spacecraft and aiming for a comparison of the dependencies observed by DEMETER and the Van Allen Probes, we first focus on the analysis of the daytime and the nighttime data separately. The results obtained for the daytime are shown in Figure 2. Figures $2 \mathrm{a}$ and $2 \mathrm{~b}$ show the median power spectral densities of magnetic field fluctuations measured by the Van Allen Probes outside and inside the plasmasphere, respectively. The median intensities are color coded as a function of the geomagnetic longitude (abscissa) and the wave frequency (ordinate) using the color scale on the right-hand side. The measurements performed in the MLT interval between 9 and $12 \mathrm{hr}$ were used, corresponding to the daytime DEMETER measurements. Figure $2 c$ shows the frequency-geomagnetic longitude dependence of the median electric power spectral density at geomagnetic latitudes lower than $60^{\circ}$ measured by DEMETER during the daytime half-orbits. Finally, Figure $2 \mathrm{~d}$ shows the longitudinal dependence of the estimated lightning power leaking to the upper ionosphere. This was calculated by considering the OTD/LIS long-term 


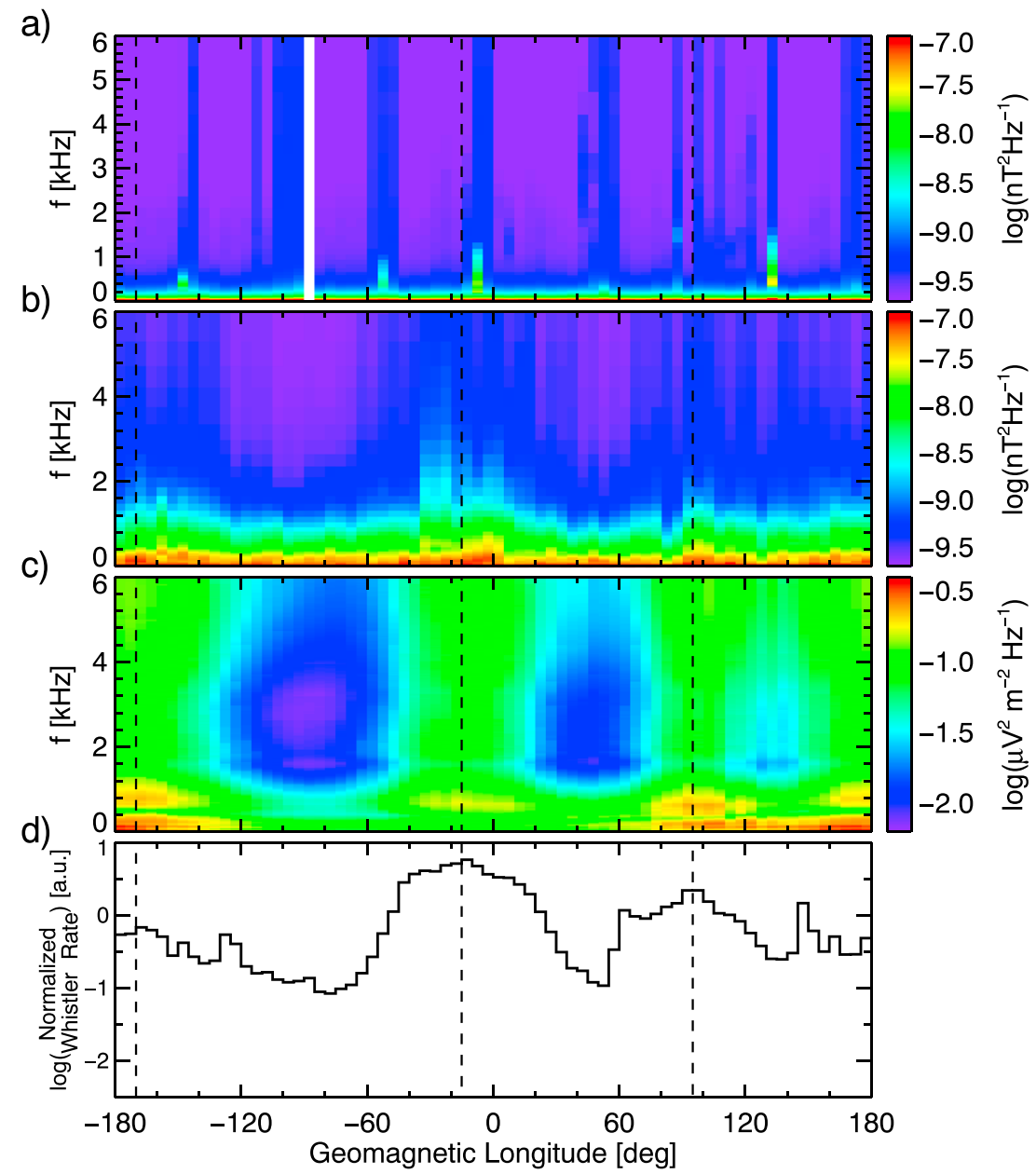

Figure 4. Same as Figure 3 but only data measured at the times of $100 \leq A E<300$ are used.

average geographic distribution of lightning activity in the MLT interval of 8-12 hr, and accounting for the attenuation characteristics of the ionosphere. We note that the slightly different MLT time interval (8-12 hr in Figure $2 \mathrm{~d}$ as compared to $9-12 \mathrm{hr}$ in Figures $2 \mathrm{a}-2 \mathrm{c}$ ) is used due to the 2-hr resolution of the OTD/LIS data. First, the provided geographic lightning occurrence maps (average number of lightning strokes per square kilometer per year) were recalculated to the geomagnetic coordinate system with spatial resolution of $2.5^{\circ}$ both in geomagnetic latitude and longitude. Then, the International Reference lonosphere (IRI) model (Bilitza \& Reinisch, 2008) was used to calculate ionospheric profiles in each $2.5^{\circ}$ interval of geomagnetic latitude, each $30^{\circ}$ interval of geomagnetic longitude, and each 2-hr local time interval at equinoxes of 1996, 1999, 2002, 2005 , and 2008. Finally, we calculated the average ionospheric profiles for each combination of local time and geomagnetic latitude (with the aforementioned resolutions preserved). These profiles are used as an input for a full wave calculation of the ionospheric attenuation (Bortnik \& Bleier, 2004; Nagano et al., 1975; Němec et al., 2008; Tao et al., 2010). Average lightning occurrence rates $\left(\mathrm{km}^{-2} /\right.$ year) multiplied by the attenuation factors for 2-kHz waves propagating from 50 - up to 1,000-km altitude are then roughly proportional the lightning power leaking out to Earth's magnetosphere, and it is further called normalized whistler rate. The vertical dashed lines mark the longitudes of the largest normalized lightning occurrence rates.

The observed longitudinal variation of the normalized whistler rate is due to the lightning occurrence being strongly confined to the landmass (e.g., Christian et al., 2003). The two main drops in the normalized whistler rate at the geomagnetic longitudes of about $-70^{\circ}$ and $60^{\circ}$ correspond to the geomagnetic longitudes of the Pacific and the Atlantic Oceans, respectively. The large ionospheric attenuation during the daytime then results in the daytime normalized whistler rates being generally rather low. As for the longitudinal dependences of the median wave intensity depicted in Figures $2 a-2 c$, no clear variation can be identified. 
a)
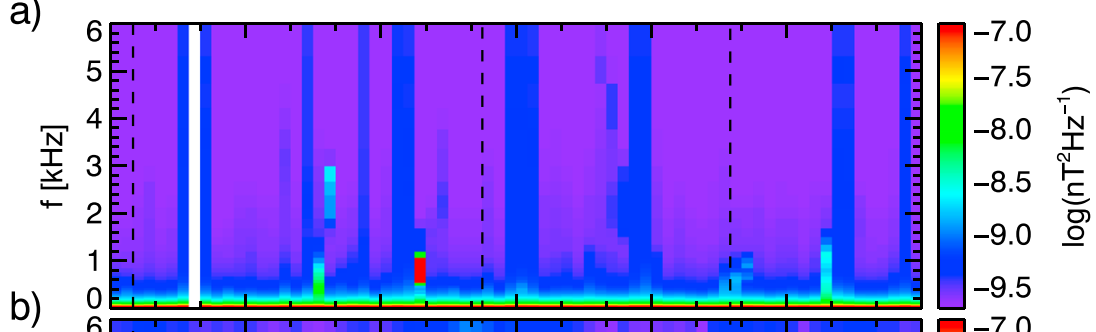

b)

c)
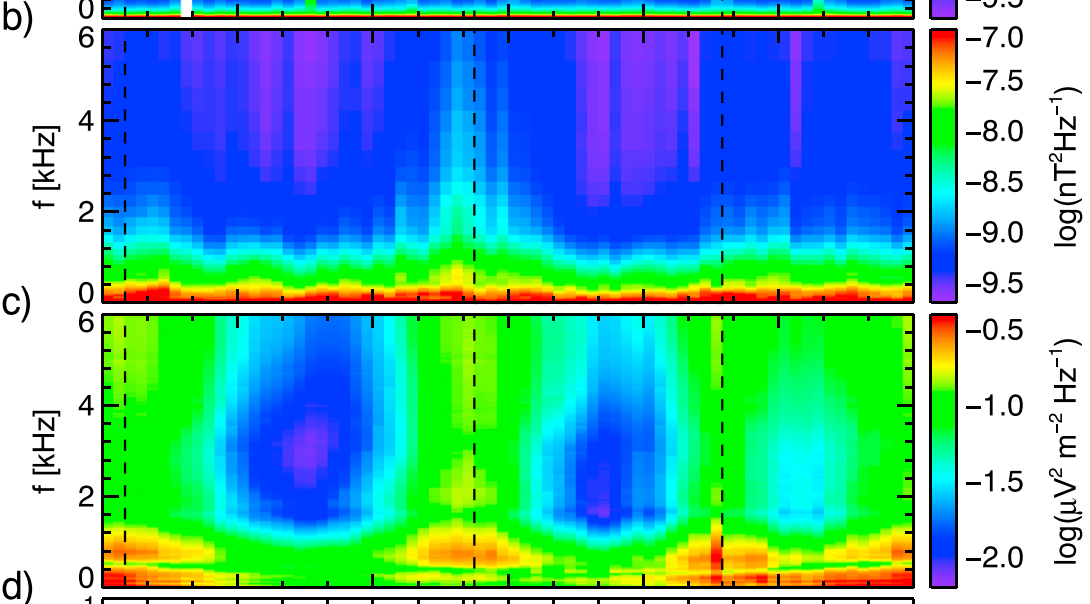

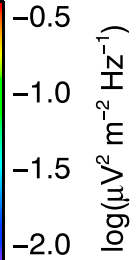

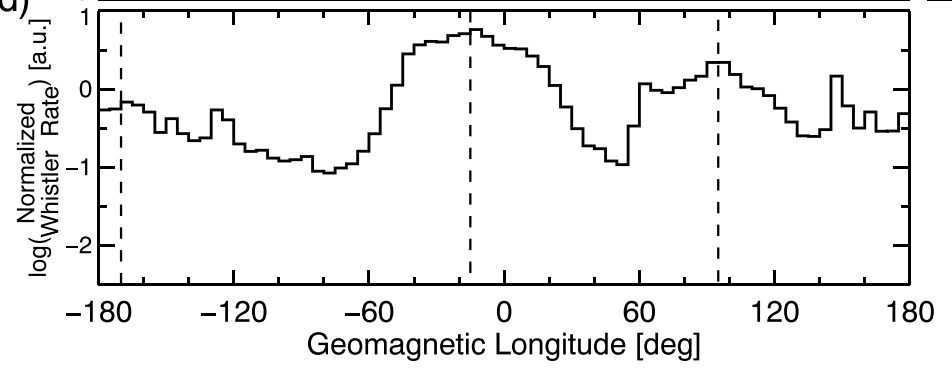

Figure 5. Same as Figure 3 but only data measured the times of $A E \geq 300$ are used.

The situation during the nighttime is rather different, as shown in Figures 3-5. They use the same format as Figure 2, but for the Van Allen Probes data measured within the MLT interval 21-24 hr, the DEMETER nighttime half-orbits, and the OTD/LIS data and attenuations characteristics in the local time interval between 20 and $24 \mathrm{hr}$. Additionally, the plotted results are distinguished according to the AE index value. Specifically, Figures $3 a-3 c, 4 a-4 c$, and $5 a-5 c$ represent the frequency-longitude dependences at times of $A E<100,100$ $\leq A E<300$, and $300 \leq A E$, respectively. The normalized whistler rate plotted in Figures $3 \mathrm{~d}$, $4 \mathrm{~d}$, and $5 \mathrm{~d}$ is the same, as the OTD/LIS data set does not allow for sorting by AE. The three figures show qualitatively rather similar results. However, the overall wave intensity inside the plasmasphere is slightly larger at the times of larger $\mathrm{AE}$ index. The same analysis of the $\mathrm{AE}$ index performed for the daytime data reveals a similar trend as during the night (not shown). Median wave intensity observed by the Van Allen Probes outside the plasmasphere (Figures $3 a, 4 a$, and $5 a$ ) is significantly lower than it was during the daytime, and no longitudinal dependence is observed. The overall wave intensity inside the plasmasphere (Figures $3 b, 4 b$, and $5 b$ ), unlike the intensity observed during the daytime, exhibits a considerable longitudinal dependence. Three distinct intensity peaks at geomagnetic longitudes of about $-160^{\circ},-20^{\circ}$, and $100^{\circ}$ can be identified at frequencies above about $0.4 \mathrm{kHz}$. During quiet times (Figure $3 \mathrm{~b}$ ), they range up to about $2 \mathrm{kHz}$. During the disturbed times (Figure $5 \mathrm{~b}$ ), the frequency extent is larger and they reach up to about $3 \mathrm{kHz}$. Median intensities at higher frequencies are significantly lower, and the longitudinal dependences cannot be observed within the displayed intensity range. At frequencies lower than $0.4 \mathrm{kHz}$, there is a band of large intensities with no identifiable longitudinal dependence. The DEMETER spacecraft, which operated at low altitudes and L-shells generally lower than 4, observes a comparable intensity pattern with three clearly distinguishable intensity peaks at frequencies of about $1 \mathrm{kHz}$. Additionally, these peaks appear to extend - with somewhat lower intensity -also to higher frequencies. One can also identify a reduced median intensity at frequencies just below about 


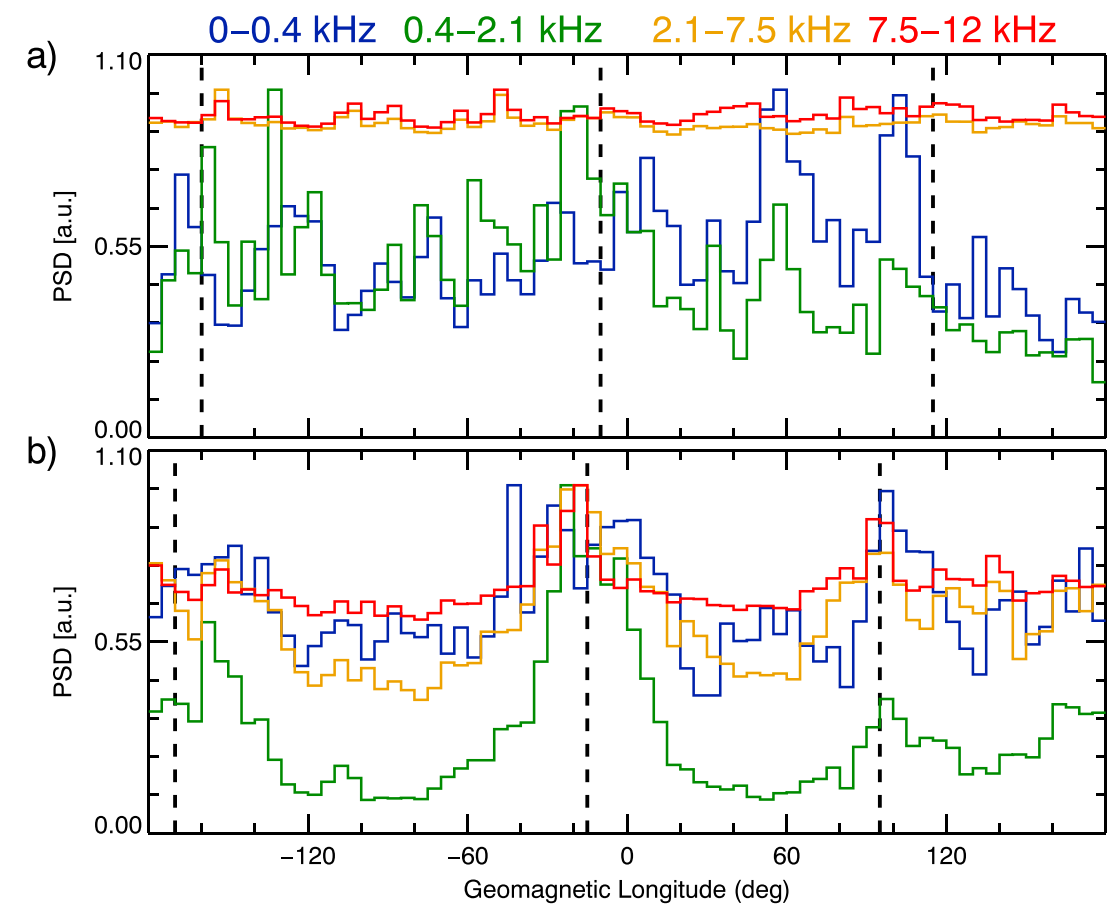

Figure 6. (a) Longitudinal dependence of median magnetic power spectral density (PSD) measured by the Van Allen Probes inside the plasmasphere in the magnetic local time interval from 9 to $12 \mathrm{hr}$. Dependences obtained in individual frequency ranges are normalized by their respective maxima and color coded according to the text on the top. The longitudes of the largest normalized lightning occurrences are marked by the dashed lines. (b) Same as (a) but for the magnetic local time interval between 21 and $24 \mathrm{hr}$.

$1.7 \mathrm{kHz}$, which corresponds to the cutoff frequency of the Earth-ionosphere waveguide (Toledo-Redondo et al., 2012). Another decrease of median intensities is observed at frequencies just below the proton gyrofrequency (about $500 \mathrm{~Hz}$ ), related to the $L=0$ cutoff frequency (Santolík, Němec, et al., 2006). Figures 3d, 4d, and $5 \mathrm{~d}$ show that the longitudes of the observed wave intensity peaks correspond to the longitudes with large normalized whistler rates, that is, to the Eastern Asia, North America, and Europe/Africa, respectively.

In order to better emphasize the longitudinal dependence, Figure 6 shows the median magnetic power spectral densities measured by the Van Allen Probes inside the plasmasphere as a function of the geomagnetic longitude. We divide the frequency range into four subintervals: (blue) below $400 \mathrm{~Hz}$, (green) between 0.4 and $2.1 \mathrm{kHz}$, (orange) from 2.1 and $7.5 \mathrm{kHz}$, and (red) between 7.5 and $12 \mathrm{kHz}$. Individual intensity profiles are normalized by their respective maxima. The dashed lines show the geomagnetic longitudes with large normalized lightning occurrence rates. Figure 6a shows the results obtained in the MLT interval from 9 to $12 \mathrm{hr}$, Figure $6 \mathrm{~b}$ displays the same for the MLT interval between 21 and $24 \mathrm{hr}$. During the day, no substantial longitudinal dependence is observed. The longitudinal dependence is, however, very well pronounced during the night. Three distinct peaks that correspond with the lightning occurrence locations are observed in green and orange curves, that is, at frequencies between 0.4 and $7.5 \mathrm{kHz}$.

The lowest frequencies where the longitudinal dependence becomes important can be estimated from Figure 7. It shows the median magnetic power spectral densities measured by the Van Allen Probes inside the plasmasphere in the MLT interval between 21 and $24 \mathrm{hr}$ in the 10 frequency channels between about 200 and $600 \mathrm{~Hz}$. The individual dependences are normalized by their respective maxima, and the dashed lines show the geomagnetic longitudes with large normalized lightning occurrence rates. It can be seen that while the longitudinal dependence is nearly absent at frequencies below about $250 \mathrm{~Hz}$, it becomes better pronounced at higher frequencies, and it is clearly discernible at frequencies higher than about $500 \mathrm{~Hz}$.

Unlike the measurements of the DEMETER spacecraft, those of the Van Allen Probes cover all MLT intervals, and also all possible combinations of MLTs and geomagnetic longitudes. Having shown that the longitudinal dependence is significantly different during the daytime than during the nighttime, it is thus of interest to investigate the situation at other MLTs. Considering that the longitudinal dependence was most pronounced 

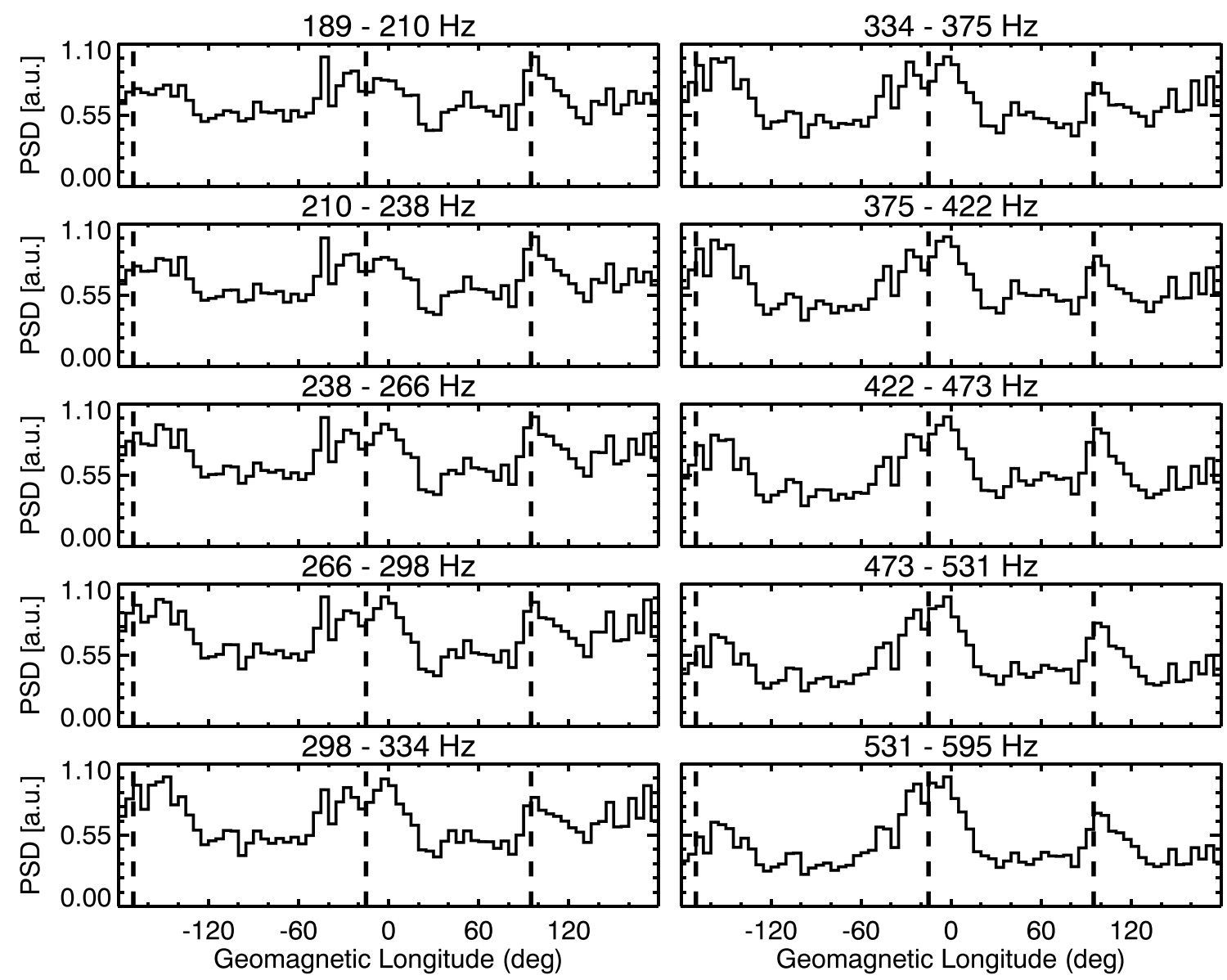

Figure 7. Median power spectral density (PSD) in selected frequency channels measured by the Van Allen Probes inside the plasmasphere in the magnetic local time interval between 21 an $24 \mathrm{hr}$. Individual dependences are normalized by their respective maxima. The longitudes of the largest normalized lightning occurrences are marked by the dashed lines.

at frequencies between about 0.4 and $2 \mathrm{kHz}$, we limit further analysis to this frequency range. Although the longitudinal dependence is observed up to higher frequencies, the overall wave intensity considerably decreases above about $2 \mathrm{kHz}$. Figure 8 a shows the resulting MLT-geomagnetic longitude dependence of the median power spectral densities observed by the Van Allen Probes inside the plasmasphere. A running 3-hr wide MLT window was used in order to obtain a reasonable number of data points in each individual bin. The numbers generally exceed 2500 and are approximately uniformly distributed, as is shown in Figure $8 \mathrm{~b}$. Figure 8 a shows that the median wave intensity exhibits a significant longitudinal variation over a wide range of MLTs, but primarily on the nightside.

The analysis of the wave propagation parameters allowed by the multicomponent Van Allen Probes measurements can be used to investigate whether the observed longitudinal dependence of the wave intensity occurs preferentially for waves with some specific propagation parameters. This is done in Figure 9 . Figures $9 \mathrm{a}$ and $9 \mathrm{~b}$ use the same format and calculation method as Figure 8 , but with the results separated according to the wave normal angle determined by the singular value decomposition method (Santolík et al., 2003). The algorithm used utilizes the plane wave simplification; therefore, only data with planarity of magnetic field fluctuations larger than 0.4 are used to ensure a reliable results. Specifically, only the intensities of waves with wave normal angles lower than $30^{\circ}$ and larger than $60^{\circ}$ were included in Figures $9 \mathrm{a}$ and $9 \mathrm{~b}$, respectively. The occurrence rate of the quasi-parallel waves is significantly larger than that of the highly oblique waves (by an order of magnitude). It can be seen that the median intensity of quasi-parallel waves (Figure 9a) is larger during the daytime than during the nighttime, and it does not exhibit any clear longitudinal dependence. The median intensity of highly oblique waves (Figure 9b) is generally lower than the intensity of quasi-parallel waves. It does, however, exhibit three distinct increases at geomagnetic longitudes corresponding to the 
a)

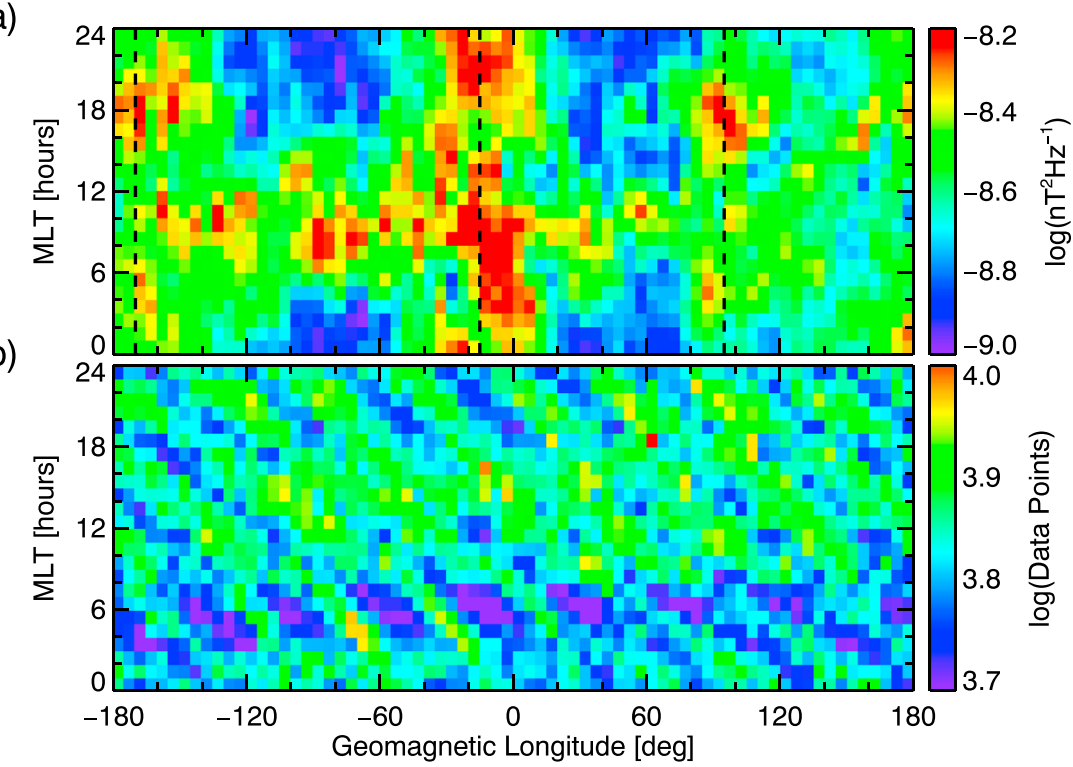

Figure 8. (a) Median magnetic power spectral density in the frequency range between 0.4 and $2 \mathrm{kHz}$ measured by Van Allen Probes inside the plasmasphere as a function of magnetic local time (MLT) and geomagnetic longitude. The dashed lines mark the longitudes of the largest normalized lightning occurrence rates. (b) Number of data points in individual bins.

aforementioned results. These intensity increases span significant ranges in MLT, principally over the entire nightside. A comparison with normalized lightning occurrence rate plotted in Figure $9 c$ reveals a striking agreement between the MLT-longitude intervals with increased median wave intensities and MLT-longitude intervals with high normalized whistler rates.

\section{a)}

$$
\text { a) }
$$

b)

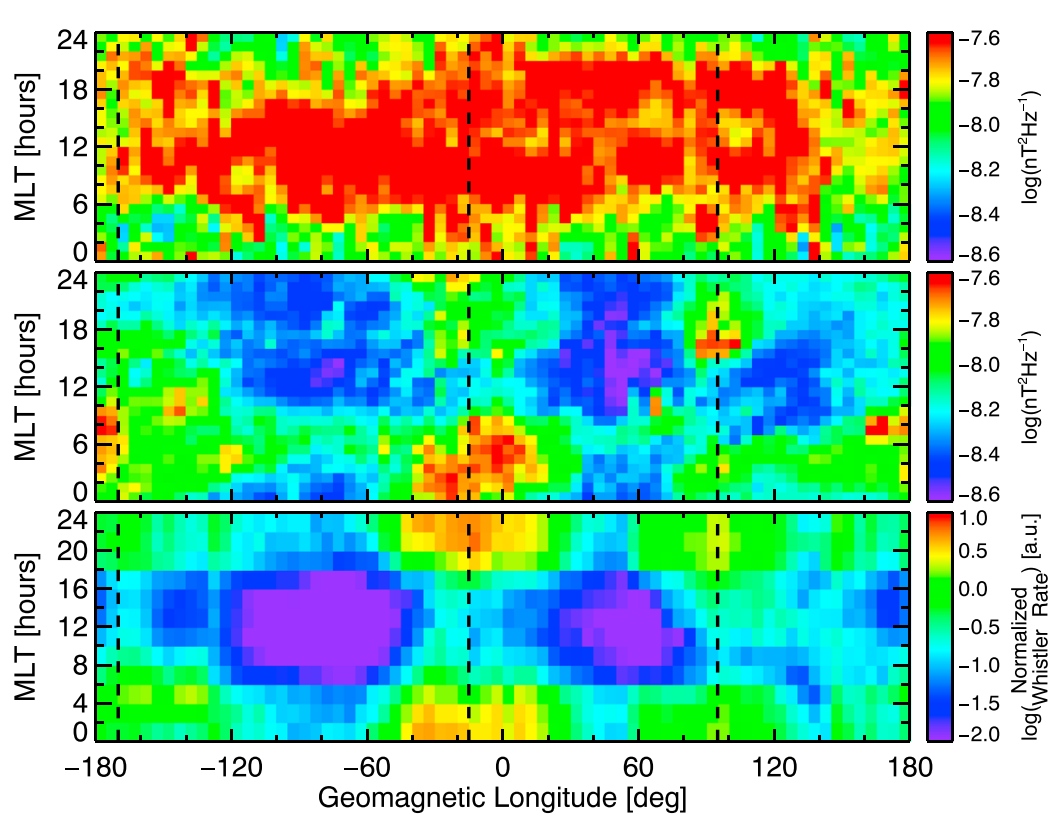

Figure 9. (a) Same as Figure 8 a but only for wave normal angles lower than $30^{\circ}$. (b) Same as Figure $8 \mathrm{a}$, but only for wave normal angles larger than $60^{\circ}$. (c) Normalized lightning occurrence rate as a function of MLT and the geomagnetic longitude. The dashed lines mark the longitudes of the largest normalized lightning occurrence rates. 


\section{Discussion}

Considering that electromagnetic waves generated by plasma instabilities at larger radial distances do not have any clear reason to exhibit a longitudinal dependence, one can assume that the observed longitudinal dependence is due to the influence coming from below, that is, due to the terrestrial effects. There are four principal possibilities why the terrestrial effects should depend on longitude. First, one may consider powerful military VLF transmitters on the ground, whose signals are readily detectable in the inner magnetosphere (Cohen \& Inan, 2012; Starks et al., 2008). However, the transmitter signals are generally narrowband and have frequencies typically well above $10 \mathrm{kHz}$ (Cohen et al., 2012), that is, beyond the analyzed frequency range. Second, one can consider an anthropogenic influence in the form of electromagnetic radiation from electric power systems on the ground. The influenced locations follow the industrialized areas well (Němec et al., 2006, 2007), and thus they exhibit a clear longitudinal dependence. However, the radiated signals are typically rather weak and narrowband (Němec et al., 2008), and their overall effect on the wave intensity in the inner magnetosphere is thus likely rather negligible (Němec, Parrot, \& Santolík, 2010). Third, the observed longitudinal dependence might be due to the asymmetric geomagnetic field. This is observed, for example, in the case of energetic particle precipitation, which is significantly larger in the South Atlantic Anomaly region (e.g., Horne et al., 2009; Zawedde et al., 2016). However, in this case, one might expect only one intensity peak to occur. Consequently, the explanation based on the final possibility, that is, lightning-generated whistlers is the most likely, and it is consistent with all other observations.

The lightning occurrence rate varies significantly as a function of geographic location, season of the year, and local time (e.g., Christian et al., 2003; Mach et al., 2011). However, the positional variation is perhaps the most striking, and we believe it to be the main reason for the observed longitudinal dependence. Specifically, lightning occurrence rate above landmasses are significantly larger than lightning occurrence rates above the oceans, that is, the average lightning occurrence at geomagnetic longitudes of the Atlantic and the Pacific Oceans is significantly lower than elsewhere. Although the lightning peak currents are on average somewhat larger above oceans than above land (Said et al., 2013; Zoghzoghy et al., 2015), the lightning energy escaping to the inner magnetosphere can be in the first approximation considered to be proportional to the number of lightning strokes. The seasonal variations of lightning occurrence are difficult to distinguish in the present analysis. While the seasonal dependence results in significant differences in lightning occurrence, with more lightning being observed during the local summer, one needs to consider that lightning-generated emissions from both hemispheres are observed by the spacecraft. Taking into account that the northern summer corresponds to the southern winter and vice versa, these seasonal variations are partially suppressed. As for the MLT dependence, two different effects need to be considered. First, the diurnal variation of the average lightning occurrence rate, which generally peaks at about 16:00 LT, reaching about 4 times the minimal value that occurs shortly before noon (Bailey et al., 2007; Colman \& Starks, 2013; Mach et al., 2011). Second, attenuation of the lightning-generated emissions during their propagation through the ionosphere varies significantly during the day. The attenuation is generally an order of magnitude larger during the daytime than during the nighttime. Additionally, the ionospheric attenuation exhibits a latitudinal dependence, with the attenuation generally lower at larger geomagnetic latitudes (Helliwell, 1965).

All these factors are properly incorporated in the calculation of the MLT-longitude dependence of the normalized whistler rate, that is, a quantity roughly proportional to the power of the lightning-generated emissions escaping the ionosphere. The good agreement between the MLT-longitude dependence of the median intensity of electromagnetic waves with highly oblique wave normals (Figure 9b) and the normalized average flash rate (Figure 9c) is a significant piece of evidence for the lightning-generated whistlers being responsible for the effect. The lack of longitudinal dependence during the daytime can be then understood in terms of the daytime ionospheric attenuation being so large that the lightning-generated whistlers escaping the ionosphere are too weak to have any significant effect. We therefore suggest that the longitudinal dependence of the median wave intensity inside the plasmasphere observed primarily during the nighttime is due to the lightning-generated whistlers. The longitudinal dependence of the wave intensities was already studied by Green et al. (2005) and Meredith, Horne, Clilverd, et al. (2006). Green et al. (2005) focused mainly on two frequency intervals, one below $330 \mathrm{~Hz}$, the other between about 0.5 and $3.0 \mathrm{kHz}$. The lower frequency range, which they attribute to equatorial electromagnetic waves, does not exhibit any longitudinal dependence, and its intensity is larger at the times of enhanced geomagnetic activity. The upper frequency range, which they attribute to the plasmaspheric hiss, qualitatively follows the lightning distribution. It is stronger during summer than during winter and also over landmass than over the ocean. All these findings principally agree 
with the results shown in the present study. However, our results show that the lightning effect is stronger on the nightside, which we attribute to the ionospheric attenuation. Meredith, Horne, Clilverd, et al. (2006) split the frequency range up to $5 \mathrm{kHz}$ into seven bands, and they identified two distinct frequency intervals with different properties. At frequencies between 0.1 and $1.0 \mathrm{kHz}$ no longitudinal dependence was observed. The emissions in this frequency range were stronger during the day, and their intensity increased with the geomagnetic activity. On the other hand, wave intensity at frequencies between about 2 and $5 \mathrm{kHz}$ behaves in the similar way as the lightning activity. The emissions in this frequency range are stronger over the landmass than over the ocean, and they peak on the nightside during northern summer. Generally, the emissions in the lower frequency interval are about an order of magnitude stronger. Our findings, however, show that the frequency range which does not follow the lightning distribution spreads only up to about $400 \mathrm{~Hz}$.

The fact that the longitudinal dependence is present only for electromagnetic waves propagating at highly oblique wave normal angles is consistent with unducted whistlers being responsible for the effect. Specifically, the ray tracing analysis of the propagation of lightning-generated unducted whistlers to larger radial distances shows that the wave normal angles close to the equatorial plane are generally very large (Bortnik et al., 2003b). It is also of interest to estimate the importance of lightning-generated waves for the processes of the radiation belt dynamics. Meredith, Horne, Glauert, et al. (2006) and Meredith et al. (2007) investigated the influence of whistler mode waves on the lifetimes of energetic electrons in the outer radiation belt. They show that extended periods of gradual loss of energetic electrons in the region $3<L<5$ occur during quiet periods following enhanced magnetic activity and that these specific decay intervals are associated with large values of ratio between the electron plasma frequency and electron cyclotron frequency, hence, inside the plasmasphere. Therefore, they focused on the effects of plasmaspheric hiss and lightning-generated whistlers. Their simulations show that the precipitation caused by the waves with low wave normal angles is nearly by an order of magnitude higher than that caused by highly oblique waves. This, along with the lower median intensity of the quasi-perpendicular waves suggests that the lightning-generated waves contribute to the precipitation only marginally.

As for why the longitudinal dependence is not observed outside of the plasmasphere, this is likely a combination of several different effects. First, the raytracing analysis of unducted whistlers reveals that there is - for a given frequency of the wave-a characteristic L-shell beyond which the emission does not propagate (Bortnik et al., 2003b). Consequently, the effects related to lightning might be expected to be limited to lower frequencies at larger radial distances. This is indeed observed, when one compares the frequency-longitude distribution observed by DEMETER at low altitudes and by the Van Allen Probes at generally larger radial distances (see Figure 3). Additionally, the unducted waves propagating inside the plasmasphere are efficiently trapped by the gradient of the refractive index at the plasmapause boundary, and it is not easy for them to escape outside (Bortnik, Chen, Li, Thorne, \& Horne., 2011; Bortnik, Chen, Li, Thorne, Meredith, \& Horne, 2011; Bortnik et al., 2008). This finding is also consistent with the results by Bell et al. (2004) and Platino et al. (2005), who reported the presence of lightning-generated whistlers outside the plasmasphere to be rather rare. Comparison of dependences obtained at the times of various geomagnetic activity levels reveals that the median wave intensities are larger during the disturbed times. Additionally, the longitudinal dependence extends to higher frequencies when $A E \geq 300$. This can likely be explained by the plasmasphere being restricted to lower L-shells during the disturbed period, and the relevant data thus measured primarily at lower radial distances.

\section{Summary}

Power spectral densities of electric/magnetic field fluctuations measured by the DEMETER and the Van Allen Probes spacecraft were investigated as a function of the geomagnetic longitude. We have shown that no longitudinal dependence is observed at frequencies lower than about $0.4 \mathrm{kHz}$ or outside the plasmasphere. On the other hand, geomagnetic longitude is an important controlling factor inside the plasmasphere at frequencies between about 0.4 and $2 \mathrm{kHz}$. The longitudinal dependence is most pronounced during the nighttime, and for waves propagating at highly oblique wave normal angles (larger than $60^{\circ}$ ). We suggest that the observed dependencies are consistent with the effect being due to lightning-generated emissions 
Acknowledgments

DEMETER was a CNES mission. We thank the engineers from CNES and scientific laboratories (CBK, IRAP, LPC2E, LPP, and SSD of ESTEC) who largely contributed to the success of this mission. DEMETER data are accessible from https://sipad-cdpp.cnes.fr. Van Allen Probes data used in this paper can be found in the EMFISIS archive http://emfisis.physics.uiowa.edu. The OTD/LIS data can be downloaded from the NASA archive https://ghrc.nsstc.nasa.gov/hydro; AE index data can be downloaded from World Data Center for Geomagnetism, Kyoto, at http://wdc.kugi.kyoto-u.ac.jp/ dstae. F. N. and J. Z. acknowledge the support of GACR grant 18-00844S and GAUK grant 300216 . The work of O. S. and I. K. was supported by MSMT grant LTAUSA 17070, GACR grant 17-07027S, and by the Praemium Academiae award from the CAS. The work at the University of lowa was supported by NASA through JHU/APL contract 921647 under NASA Prime contract NAS5-01072. propagating through the ionosphere and resulting in unducted whistlers propagating within the plasmasphere. Average lightning occurrence rates normalized by the ionospheric attenuation factor were used to support this claim, showing a remarkable agreement with the observed dependence. Our results indicate that lightning-generated whistlers contribute to the intensity of whistler mode waves in the plasmasphere, being most effective on the nightside at frequencies in the range $400 \mathrm{~Hz}$ to $2 \mathrm{kHz}$.

\section{References}

Abel, B., \& Thorne, R. M. (1998a). Electron scattering loss in Earth's inner magnetosphere: 1. Dominant physical processes. Journal of Geophysical Research, 103(A2), 2385-2396. https://doi.org/10.1029/97JA02919

Abel, B., \& Thorne, R. M. (1998b). Electron scattering loss in Earth's inner magnetosphere: 2. Sensitivity to model parameters. Journal of Geophysical Research, 103(A2), 2397-2407. https://doi.org/10.1029/97JA02920

Bailey, J. C., Blakeslee, R. J., Buechler, D. E., \& Christian, H. J. (2007). Diurnal lightning distributions as observed by the Optical Transient Detector (OTD) and the Lightning Imaging Sensor (LIS). In 13th International Conference on Atmospheric Electricity, 13-17 Aug. 2007, Beijing, China.

Bell, T. F., Inan, U. S., Platino, M., Pickett, J. S., Kossey, P. A., \& Kennedy, E. J. (2004). CLUSTER observations of lower hybrid waves excited at high altitudes by electromagnetic whistler mode signals from the HAARP facility. Geophysical Research Letters, 31 , L06811. https://doi.org/10.1029/2003GL018855

Berthelier, J.-J., Godefroy, M., Leblanc, F., Malingre, M., Menvielle, M., Lagoutte, D., et al. (2006). ICE, the electric field experiment on DEMETER. Planetary and Space Science, 54(5), 456-471. https://doi.org/10.1016/j.pss.2005.10.016

Bilitza, D., \& Reinisch, B. W. (2008). International Reference lonosphere 2007: Improvements and new parameters. Advances in Space Research, 42(4), 599-609. https://doi.org/10.1016/j.asr.2007.07.048

Bortnik, J., \& Bleier, T. (2004). Full wave calculation of the source characteristics of seismogenic electromagnetic signals as observed at LEO satellite altitudes. Abstract T51B-0453 Presented at the 2004 AGU Fall Meeting, San Francisco, CA.

Bortnik, J., Chen, L., Li, W., Thorne, R. M., \& Horne, R. B. (2011). Modeling the evolution of chorus waves into plasmaspheric hiss. Journal of Geophysical Research, 116, A08221. https://doi.org/10.1029/2011JA016499

Bortnik, J., Chen, L., Li, W., Thorne, R. M., Meredith, N. P., \& Horne, R. B. (2011). Modeling the wave power distribution and characteristics of plasmaspheric hiss. Journal of Geophysical Research, 116, A12209. https://doi.org/10.1029/2011JA016862

Bortnik, J., Inan, U. S., \& Bell, T. F. (2003a). Frequency-time spectra of magnetospherically reflecting whistlers in the plasmasphere. Journal of Geophysical Research, 108(A1), 1030. https://doi.org/10.1029/2002JA009387

Bortnik, J., Inan, U. S., \& Bell, T. F. (2003b). Energy distribution and lifetime of magnetospherically reflecting whistlers in the plasmasphere. Journal of Geophysical Research, 108(A5), 1199. https://doi.org/10.1029/2002JA009316

Bortnik, J., Inan, U. S., \& Bell, T. F. (2006). Temporal signatures of radiation belt electron precipitation induced by lightning-generated MR whistler waves: 2. Global signatures. Journal of Geophysical Research, 111, A02205. https://doi.org/10.1029/2005JA011398

Bortnik, J., Li, W., Thorne, R. M., Angelopoulos, V., Cully, C., Bonnell, J., et al. (2009). An observation linking the origin of plasmaspheric hiss to discrete chorus emissions. Science, 324(5928), 775-778. https://doi.org/10.1126/science.1171273

Bortnik, J., Thorne, R. M., \& Meredith, N. P. (2008). The unexpected origin of plasmaspheric hiss from discrete chorus emissions. Nature, 452(7183), 62-66. https://doi.org/10.1038/nature06741

Burtis, W. J., \& Helliwell, R. A. (1969). Banded chorus - A new type of VLF radiation observed in the magnetosphere by OGO 1 an OGO 3. Journal of Geophysical Research, 74(11), 3002-3010. https://doi.org/10.1029/JA074i011p03002

Cecil, D. J., Buechler, D. E., \& Blakeslee, R. J. (2014). Gridded lightning climatology from TRMM-LIS and OTD: Dataset description. Atmospheric Research, 135, 404-414. https://doi.org/10.1016/j.atmosres.2012.06.028

Chen, L., Bortnik, J., Li, W., Thorne, R. M., \& Horne, R. B. (2012a). Modeling the properties of plasmaspheric hiss: 1. Dependence on chorus wave emission. Journal of Geophysical Research, 117, A05201. https://doi.org/10.1029/2011JA017201

Chen, L., Bortnik, J., Li, W., Thorne, R. M., \& Horne, R. B. (2012b). Modeling the properties of plasmaspheric hiss: 2. Dependence on the plasma density distribution. Journal of Geophysical Research, 117, A05202. https://doi.org/10.1029/2011JA017202

Chen, L., Li, W., Bortnik, J., \& Thorne, R. M. (2012). Amplification of whistler-mode hiss inside the plasmasphere. Geophysical Research Letters, 39, L08111. https://doi.org/10.1029/2012GL051488

Christian, H. J., Blakeslee, R. J., Boccippio, D. J., Boeck, W. L., Buechler, D. E., Driscoll, K. T., et al. (2003). Global frequency and distribution of lightning as observed from space by the Optical Transient Detector. Journal of Geophysical Research, 108(D1), 4005. https://doi.org/10.1029/2002JD002347

Chum, J., \& Santolík, O. (2005). Propagation of whistler-mode chorus to low altitudes: Divergent ray trajectories and ground accessibility Annales Geophysicae, 23(12), 3727-3738. https://doi.org/10.5194/angeo-23-3727-2005

Church, S. R., \& Thorne, R. M. (1983). On the origin of plasmaspheric hiss: Ray path integrated amplification. Journal of Geophysical Research, 88(A10), 7941-7957. https://doi.org/10.1029/JA088iA10p07941

Cohen, M. B., \& Inan, U. S. (2012). Terrestrial VLF transmitter injection into the magnetosphere. Journal of Geophysical Research, 117, A08310. https://doi.org/10.1029/2012JA017992

Cohen, M. B., Lehtinen, N. G., \& Inan, U. S. (2012). Models of ionospheric VLF absorption of powerful ground based transmitters. Geophysical Research Letters, 39, L24101. https://doi.org/10.1029/2012GL054437

Colman, J. J., \& Starks, M. J. (2013). VLF wave intensity in the plasmasphere due to tropospheric lightning. Journal of Geophysical Research: Space Physics, 118, 4471-4482. https://doi.org/10.1002/jgra.50217

Draganov, A. B., Inan, U. S., Sonwalkar, V. S., \& Bell, T. F. (1992). Magnetospherically reflected whistlers as a source of plasmaspheric hiss. Geophysical Research letters, 19(3), 233-236. https://doi.org/10.1029/91GL03167

Fišer, J., Chum, J., Diendorfer, G., Parrot, M., \& Santolík, O. (2010). Whistler intensities above thunderstorms. Annales Geophysicae, $28,37-46$. https://doi.org/10.5194/angeo-28-37-2010

Green, J. L., Boardsen, S., Garcia, L., Fung, S. F., \& Reinisch, B. W. (2006). Reply to "Comment on "On the origin of whistler mode radiation in the plasmasphere" by Green et al."Journal of Geophysical Research, 111, A09211. https://doi.org/10.1029/2006JA011622

Green, J. L., Boardsen, S., Garcia, L., Taylor, W. W. L., Fung, S. F., \& Reinisch, B. W. (2005). On the origin of whistler mode radiation in the plasmasphere. Journal of Geophysical Research, 110, A03201. https://doi.org/10.1029/2004JA010495

Hayakawa, M., \& Sazhin, S. S. (1992). Mid-latitude and plasmaspheric hiss: A review. Planetary and Space Science, 40(10), $1325-1338$. https://doi.org/10.1016/0032-0633(92)90089-7 
Helliwell, R. A. (1965). Whistlers and Related lonospheric Phenomena (Vol. 50). Stanford, California: Stanford University Press.

Horne, R. B., Lam, M. M., \& Green, J. C. (2009). Energetic electron precipitation from the outer radiation belt during geomagnetic storms. Geophysical Research Letters, 36, L19104. https://doi.org/10.1029/2009GL040236

Inan, U. S., Piddyachiy, D., Peter, W. B., Sauvaud, J. A., \& Parrot, M. (2007). DEMETER satellite observations of lightning-induced electron precipitation. Geophysical Research Letters, 34, L07103. https://doi.org/10.1029/2006GL029238

Kletzing, C. A., Kurth, W. S., Acuna, M., MacDowall, R. J., Torbert, R. B., Averkamp, T., et al. (2013). The Electric and Magnetic Field Instrument Suite and Integrated Science (EMFISIS) on RBSP. Space Science Reviews, 179(1-4), 127-181. https://doi.org/10.1007/s11214-013-9993-6

Kurth, W. S., De Pascuale, S., Faden, J. B., Kletzing, C. A., Hospodarsky, G. B., Thaller, S., \& Wygant, J. R. (2015). Electron densities inferred from plasma wave spectra obtained by the Waves instrument on Van Allen Probes. Journal of Geophysical Research: Space Physics, 120, 904-914. https://doi.org/10.1002/2014JA020857

Laakso, H., Santolik, O., Horne, R., Kolmasová, I., Escoubet, P., Masson, A., \& Taylor, M. (2015). Identifying the source region of plasmaspheric hiss. Geophysical Research Letters, 42, 3141 -3149. https://doi.org/10.1002/2015GL063755

Li, W., Chen, L., Bortnik, J., Thorne, R. M., Angelopoulos, V., Kletzing, C. A., et al. (2015). First evidence for chorus at a large geocentric distance as a source of plasmaspheric hiss: Coordinated THEMIS and Van Allen Probes observation. Geophysical Research Letters, $42,241-248$. https://doi.org/10.1002/2014GL062832

Li, W., Thorne, R. M., Angelopoulos, V., Bonnell, J. W., McFadden, J. P., Carlson, C. W., et al. (2009). Evaluation of whistler-mode chorus intensification on the nightside during an injection event observed on the THEMIS spacecraft. Journal of Geophysical Research, 114, A00C14. https://doi.org/10.1029/2008JA013554

Li, W., Thorne, RM, Bortnik, J., Reeves, GD, Kletzing, CA, Kurth, WS, et al. (2013). An unusual enhancement of low-frequency plasmaspheric hiss in the outer plasmasphere associated with substorm-injected electrons. Geophysical Research Letters, 40, 3798-3803. https://doi.org/10.1002/grl.50787

Li, W., Thorne, R. M., Meredith, N. P., Horne, R. B., Bortnik, J., Shprits, Y. Y., \& Ni, B. (2008). Evaluation of whistler mode chorus amplification during an injection event observed on CRRES. Journal of Geophysical Research, 113, A09210. https://doi.org/10.1029/2008JA013129

Lyons, L. R., \& Thorne, R. M. (1973). Equilibrium structure of radiation belt electrons. Journal of Geophysical Research, 78(13), 2142-2149. https://doi.org/10.1029/JA078i013p02142

Mach, D. M., Blakeslee, R. J., \& Bateman, M. G. (2011). Global electric circuit implications of combined aircraft storm electric current measurements and satellite-based diurnal lightning statistics. Journal of Geophysical Research, 116, D05201. https://doi.org/10.1029/2010JD014462

Meredith, N. P., Horne, R. B., \& Anderson, R. R. (2001). Substorm dependence of chorus amplitudes: Implications for the acceleration of electrons to relativistic energies. Journal of Geophysical Research, 106(A7), 13,165-13,178. https://doi.org/10.1029/2000JA900156

Meredith, N. P., Horne, R. B., Clilverd, M. A., Horsfall, D., Thorne, R. M., \& Anderson, R. R. (2006). Origins of plasmaspheric hiss. Journal of Geophysical Research, 111, A09217. https://doi.org/10.1029/2006JA011707

Meredith, N. P., Horne, R. B., Glauert, S. A., \& Anderson, R. R. (2007). Slot region electron loss timescales due to plasmaspheric hiss and lightning-generated whistlers. Journal of Geophysical Research, 112, A08214. https://doi.org/10.1029/2007JA012413

Meredith, N. P., Horne, R. B., Glauert, S. A., Baker, D. N., Kanekal, S. G., \& Albert, J. M. (2009). Relativistic electron loss timescales in the slot region. Journal of Geophysical Research, 114, A03222. https://doi.org/10.1029/2008JA013889

Meredith, N. P., Horne, R. B., Glauert, S. A., Thorne, R. M., Summers, D., Albert, J. M., \& Anderson, R. R. (2006). Energetic outer zone electron loss timescales during low geomagnetic activity. Journal of Geophysical Research, 111, A05212. https://doi.org/10.1029/2005JA011516

Meredith, N. P., Horne, R. B., Thorne, R. M., Summers, D., \& Anderson, R. R. (2004). Substorm dependence of plasmaspheric hiss. Journal of Geophysical Research, 109, A06209. https://doi.org/10.1029/2004JA010387

Němec, F., Parrot, M., \& Santolík, O. (2010). Influence of power line harmonic radiation on the VLF wave activity in the upper ionosphere: Is it capable to trigger new emissions? Journal of Geophysical Research, 115, A11301. https://doi.org/10.1029/2010JA015718

Němec, F., Santolík, O., Parrot, M., \& Berthelier, J. J. (2006). Power line harmonic radiation (PLHR) observed by the DEMETER spacecraft. Journal of Geophysical Research, 111, A04308. https://doi.org/10.1029/2005JA011480

Němec, F., Santolík, O., Parrot, M., \& Berthelier, J. J. (2007). Power line harmonic radiation: A systematic study using DEMETER spacecraft. Advances in Space Research, 40(3), 398-403. https://doi.org/10.1016/j.asr.2007.01.074

Němec, F., Santolík, O., Parrot, M., \& Bortnik, J. (2008). Power line harmonic radiation observed by satellite: Properties and propagation through the ionosphere. Journal of Geophysical Research, 113, A08317. https://doi.org/10.1029/2008JA013184

Němec, F., Santolík, O., Parrot, M., \& Rodger, C. J. (2010). Relationship between median intensities of electromagnetic emissions in the VLF range and lightning activity. Journal of Geophysical Research, 115, A08315. https://doi.org/10.1029/2010JA015296

Nagano, l., Mambo, M., \& Hutatsuishi, G. (1975). Numerical calculation of electromagnetic waves in an anisotropic multilayered medium. Radio Science, 10(6), 611-617. https://doi.org/10.1029/RS010i006p00611

Ni, B., Bortnik, J., Thorne, R. M., Ma, Q., \& Chen, L. (2013). Resonant scattering and resultant pitch angle evolution of relativistic electrons by plasmaspheric hiss. Journal of Geophysical Research: Space Physics, 118, 7740-7751. https://doi.org/10.1002/2013JA019260

Omura, Y., Katoh, Y., \& Summers, D. (2008). Theory and simulation of the generation of whistler-mode chorus. Journal of Geophysical Research, 113, A04223. https://doi.org/10.1029/2007JA012622

Parrot, M., Benoist, D., Berthelier, JJ, Blecki, J., Chapuis, Y., Colin, F., et al. (2006). The magnetic field experiment IMSC and its data processing onboard DEMETER: Scientific objectives, description and first results. Planetary and Space Science, 54(5), 441-455. https://doi.org/10.1016/j.pss.2005.10.015

Peter, W. B., \& Inan, U. S. (2004). On the occurrence and spatial extent of electron precipitation induced by oblique nonducted whistler waves. Journal of Geophysical Research, 109, A12215. https://doi.org/10.1029/2004JA010412

Peter, W. B., \& Inan, U. S. (2007). A quantitative comparison of lightning-induced electron precipitation and VLF signal perturbations. Journal of Geophysical Research, 112, A12212. https://doi.org/10.1029/2006JA012165

Platino, M., Inan, U. S., Bell, T. F., Gurnett, D. A., Pickett, J. S., Canu, P., \& Décréau, P. M. E. (2005). Whistlers observed by the Cluster spacecraft outside the plasmasphere. Journal of Geophysical Research, 110, A03212. https://doi.org/10.1029/2004JA010730

Said, R. K., Cohen, M. B., \& Inan, U. S. (2013). Highly intense lightning over the oceans: Estimated peak currents from global GLD360 observations. Journal of Geophysical Research: Atmospheres, 118, 6905-6915. https://doi.org/10.1002/jgrd.50508

Santolík, O., \& Chum, J. (2009). The origin of plasmaspheric hiss. Science, 324(5928), 729-730. https://doi.org/10.1126/science.1172878

Santolík, O., Chum, J., Parrot, M., Gurnett, D. A., Pickett, J. S., \& Cornilleau-Wehrlin, N. (2006). Propagation of whistler mode chorus to low altitudes: Spacecraft observations of structured ELF hiss. Journal of Geophysical Research, 111, A10208. https://doi.org/10.1029/2005JA011462

Santolík, O., \& Gurnett, D. A. (2002). Propagation of auroral hiss at high altitudes. Geophysical Research Letters, $29(10), 1481$. https://doi.org/10.1029/2001GL013666 
Santolík, O., Lefeuvre, F., Parrot, M., \& Rauch, J. (2001). Complete wave-vector directions of electromagnetic emissions: Application to INTERBALL-2 measurements in the nightside auroral zone. Journal of Geophysical Research, 106(A7), 13,191-13,201. https://doi.org/10.1029/2000JA000275

Santolík, O., Macúšová, E., Kolmašová, I., Cornilleau-Wehrlin, N., \& Conchy, Y. (2014). Propagation of lower-band whistler-mode waves in the outer Van Allen belt: Systematic analysis of 11 years of multi-component data from the Cluster spacecraft. Geophysical Research Letters, 41, 2729-2737. https://doi.org/10.1002/2014GL059815

Santolík, O., Němec, F., Parrot, M., Lagoutte, D., Madrias, L., \& Berthelier, J. J. (2006). Analysis methods for multi-component wave measurements on board the DEMETER spacecraft. Planetary and Space Science, 54(5), 512-527. https://doi.org/10.1016/j.pss.2005.10.020

Santolík, O., Parrot, M., Inan, U. S., Burešová, D., Gurnett, D. A., \& Chum, J. (2009). Propagation of unducted whistlers from their source lightning: A case study. Journal of Geophysical Research, 114, A03212. https://doi.org/10.1029/2008JA013776

Santolík, O., Parrot, M., \& Lefeuvre, F. (2003). Singular value decomposition methods for wave propagation analysis. Radio Science, 38(1), 1010. https://doi.org/10.1029/2000RS002523

Santolík, O., Pickett, J. S., Gurnett, D. A., Menietti, J. D., Tsurutani, B. T., \& Verkhoglyadova, O. (2010). Survey of Poynting flux of whistler mode chorus in the outer zone. Journal of Geophysical Research, 115, A00F13. https://doi.org/10.1029/2009JA014925

Sonwalkar, V. S., \& Inan, U. S. (1989). Lightning as an embryonic source of VLF hiss. Journal of Geophysical Research, 94(A6), 6986-6994. https://doi.org/10.1029/JA094iA06p06986

Starks, M. J., Quinn, R. A., Ginet, G. P., Albert, J. M., Sales, G. S., Reinisch, B. W., \& Song, P. (2008). Illumination of the plasmasphere by terrestrial very low frequency transmitters: Model validation. Journal of Geophysical Research, 113, A09320. https://doi.org/10.1029/2008JA013112

Stix, T. H. (1992). Waves in Plasmas. Basingstoke, UK: Springer Science \& Business Media.

Tao, X., Bortnik, J., \& Friedrich, M. (2010). Variance of transionospheric VLF wave power absorption. Journal of Geophysical Research, 115, A07303. https://doi.org/10.1029/2009JA015115

Thorne, R. M., Horne, R. B., \& Meredith, N. P. (2006). Comment on "On the origin of whistler mode radiation in the plasmasphere" by Green et al.Journal of Geophysical Research, 111, A09210. https://doi.org/10.1029/2005JA011477

Thorne, R. M., Li, W., Ni, B., Ma, Q., Bortnik, J., Baker, D. N., et al. (2013). Evolution and slow decay of an unusual narrow ring of relativistic electrons near $L \sim 3.2$ following the September 2012 magnetic storm. Geophysical Research Letters, 40, 3507-3511. https://doi.org/10.1002/grl.50627

Thorne, R. M., Smith, E. J., Burton, R. K., \& Holzer, R. E. (1973). Plasmaspheric hiss. Journal of Geophysical Research, $78(10), 1581-1596$. https://doi.org/10.1029/JA078i010p01581

Toledo-Redondo, S., Parrot, M., \& Salinas, A. (2012). Variation of the first cut-off frequency of the Earth-ionosphere waveguide observed by DEMETER. Journal of Geophysical Research, 117, A04321. https://doi.org/10.1029/2011JA017400

Tsurutani, B. T., Falkowski, B. J., Verkhoglyadova, O. P., Pickett, J. S., Santolík, O., \& Lakhina, G. S. (2012). Dayside ELF electromagnetic wave survey: A Polar statistical study of chorus and hiss. Journal of Geophysical Research, 117, A00L12. https://doi.org/10.1029/2011JA017180

Tsurutani, B. T., \& Smith, E. J. (1974). Postmidnight chorus: A substorm phenomenon. Journal of Geophysical Research, 79(1), $118-127$.

Tsurutani, B. T., \& Smith, E. J. (1977). Two types of magnetospheric ELF chorus and their substorm dependences. Journal of Geophysical Research, 82(32), 5112-5128. https://doi.org/10.1029/JA082i032p05112

Walker, A. D. M. (1976). The theory of whistler propagation. Reviews of Geophysics, 14(4), 629-638.

Zawedde, A. E., Nesse Tyssøy, H., Hibbins, R., Espy, P. J., Ødegaard, L.-K. G., Sandanger, M. I., \& Stadsnes, J. (2016). The impact of energetic electron precipitation on mesospheric hydroxyl during a year of solar minimum. Journal of Geophysical Research: Space Physics, 121 5914-5929. https://doi.org/10.1002/2016JA022371

Zoghzoghy, F. G., Cohen, M. B., Said, R. K., Lehtinen, N. G., \& Inan, U. S. (2015). Shipborne LF-VLF oceanic lightning observations and modeling. Journal of Geophysical Research: Atmospheres, 120, 10,890-10,902. https://doi.org/10.1002/2015JD023226 